\title{
Efecto de la Temperatura en la Supervivencia Embrionaria y Primeros Estadios Larvales de Psetta maxima
}

\author{
Temperature Effect on Embryonic Survival and Early Larval Stages of Psetta maxima
}

\author{
${ }^{*, * *}$ Renzo Pepe-Victoriano; ${ }^{* * * * * * * * *}$ Miguel Araya $\&{ }^{* * * * * *}$ Víctor Faúndez
}

PEPE-VICTORIANO, R.; ARAYA, M. \& FAÚNDEZ, V. Efecto de la temperatura en la supervivencia embrionaria y primeros estadios larvales de Psetta maxima. Int. J. Morphol., 30(4):1551-1557, 2012.

RESUMEN: La tasa de mortalidad en las etapas embrionarias y larvales de los peces marinos se asocia al éxito de un cultivo y es necesario optimizar los procedimientos de este a nivel de desarrollo embrionario y primeros estadios larvales para una óptima supervivencia larval y una mejor producción de juveniles. Para evaluar el efecto de la temperatura en la supervivencia embrionaria y larvaria del turbot, los huevos fecundados de dos reproductores se trasladaron a estanques cónicos de incubación a tres diferentes temperaturas $\left(12,5 ; 15,5\right.$ y $\left.18,5^{\circ} \mathrm{C}\right)$. Los huevos que se encontraban a temperaturas extremas $\left(12,5\right.$ y $\left.18,5^{\circ} \mathrm{C}\right)$ tuvieron un menor desarrollo embriológico, con un porcentaje de mortalidad diaria significativamente mayor en los tres primeros días y al término de la incubación, especialmente durante la eclosión de los huevos (supervivencia del 10\%), y sin variaciones al término del experimento, cuando las larvas tenían seis días de vida. La duración del desarrollo embrionario hasta la eclosión del huevo también estuvo determinada por la temperatura de incubación, con un mayor número de huevos eclosionados y cosechados a la temperatura de $15,5^{\circ} \mathrm{C}$ (supervivencia de un $20 \%$ ). Las diferencias significativas en el desarrollo embriológico del turbot a tres diferentes temperaturas de incubación demuestran la importancia de este parámetro en la viabilidad del desarrollo embrionario y los primeros estadios larvales de P. maxima.

PALABRAS CLAVE: Huevos de peces; Turbot; Larvas de peces.

\section{INTRODUCCIÓN}

La calidad de los huevos de peces puede verse afectada por la condición de los progenitores, sincronización del ciclo de puesta, factores genéticos y también por las características intrínsecas del huevo, entre otros factores (Bromage, 1995; Brooks et al., 1997). Kjorsvik et al. (1984) sugieren que la simetría de la célula en los primeros estadios de división sería un probable indicador general de la calidad de huevos para los peces marinos. Este criterio morfológico ha sido el más confiable hasta ahora. Correlaciones positivas y significativas entre la calidad del huevo observada en las etapas más tempranas de los estadios, los criterios morfológicos, la fertilización y la división en sus primeros estadios, pueden ser indicativos de la calidad del huevo, pero no nos dicen nada sobre que factores determinan esta calidad.

La tasa de mortalidad en las etapas embrionarias y larvales es un factor importante en la determinación del éxi- to de un cultivo y así del éxito de la industria acuícola. Las pequeñas diferencias en las etapas tempranas de la vida pueden generar discrepancias importantes en la abundancia o la supervivencia final (Houde, 1987).

Durante el proceso de incubación de los huevos del turbot, Psetta maxima (Linnaeus, 1758), los factores más importantes para obtener un buen porcentaje de embriones y larvas son la calidad de los mismos, debido a una higiene apropiada durante su manejo y a las características del agua de mar usada en el cultivo (Barton, 1981; Jones, 1989). Otro factor que puede tener un efecto importante en el desarrollo embrionario es el tipo de flujo utilizado y que depende principalmente de las características del agua de mar en el área, siendo la temperatura y la salinidad los factores que pueden causar disturbios e interrupciones en el desarrollo del pez. Diversos estudios examinaron la influencia de la temperatura en los índices del desarrollo y de la mortalidad de los

* Centro de Recursos Naturales y Medio Ambiente (CERENAYMA), Escuela Universitariade Ingeniería Industrial e Informáticay Sistema (EUIIIS), Universidad de Tarapacá, Arica, Chile.

** Programa de Doctorado en Ciencias, Mención Biología. Departamento de Biología, Universidad de Tarapacá, Arica, Chile.

*** Programa de Doctorado en Ciencias Aplicadas mención Sistemas Marinos Costeros, Universidad de Antofagasta, Antofagasta, Chile.

***** Dirección actual. Facultad de Recursos Naturales Renovables, Unversidad Arturo Prat, Iquique, Chile.

****** Departamento de Ingeniería Ambiental y Recursos Naturales, Universidad Católica de la Santísima Concepción, Concepción, Chile. 
embriones de los peces (Van der Land, 1991; Le Clus \& Malan, 1995), pero estos mecanismos relacionados con la temperatura siguen siendo confusos para muchas especies (Legget \& Deblois, 1994). Ryland \& Nichols (1967) indicaron que el tamaño de las larvas en la primera alimentación está relacionado con el tamaño inicial del huevo y la eficacia en que el saco vitelino se convierte al tejido fino del cuerpo. Ambos factores son ayudados por la temperatura óptima en incubación.

El objetivo del presente estudio, fue determinar el efecto de la temperatura en la supervivencia embrionaria y en los primeros estadios de desarrollo larval de Psetta maxima, con el fin de maximizar la producción de larvas.

\section{MATERIAL Y MÉTODO}

Se realizaron desoves de dos hembras reproductores de turbot provenientes de un criadero comercial, ubicado en la localidad de Las Cruces, Chile en los 33⒉'46"'S 71³7'39"O. Cada hembra había sido marcada previamente con un chip electrónico para su identificación y una vez seleccionadas, se indujo al desove mediante masaje abdominal. Al comenzar el desove los óvulos de cada hembra fueron depositados en recipientes plásticos de 51 de capacidad. Posteriormente se seleccionaron los machos procediendo a la extracción del esperma del mismo modo que a las hembras para inmediatamente después proceder a la fecundación de los óvulos. Los huevos de cada hembra se distribuyeron por separado en tres recipientes plásticos y se mantuvieron cubiertos con agua de mar a tres temperaturas diferentes $\left(12,5^{\circ}, 15,5^{\circ}\right.$ y $\left.18,5^{\circ} \mathrm{C}\right)$, retirando después de $10 \mathrm{~min}$ los huevos no viables. Se contabilizó el número de huevos obtenidos en cada recipiente, se dividió en dos porciones iguales, para incorporarlos a los estanques cónicos de incubación de una capacidad de 501 , en ellos se sembraron a una densidad de 2 a 3 huevos por ml. Los estanques se mantuvieron a $15,5^{\circ} \mathrm{C}$ (estanques control n 1 y 2 ), $12,5^{\circ} \mathrm{C}$ (estanques n 3 y 4 ) y $18,5^{\circ} \mathrm{C}$ (estanques n 5 y 6 ) para cada hembra por separado (Tabla I). La temperatura se mantuvo a través de tres estanques externos acondicionados con temperaturas de 12,5, 15,5 y $18,5^{\circ} \mathrm{C}$. Para mantener los $12,5^{\circ} \mathrm{C}$ se extrajo agua de un enfriador y se mantuvo en un estanque de 6001 trasladándose a los estanques de incubación 3 y 4 a razón de 1,51/min. Para obtener el agua a $18,5^{\circ} \mathrm{C}$ se introdujeron dos calefactores de $200 \mathrm{~W}$, regulando automáticamente la temperatura de esta, entregándole un flujo a razón de 1,5 l/min a los estanques 5 y 6 de incubación. Para los estanques controles se mantenía un estanque de $600 \mathrm{l}$, el cual era mantenido a una temperatura constante, ayudado por un calefactor de $300 \mathrm{~W}$, el cual regulaba automáticamente la temperatura de este.
Todos los estanques cónicos de incubación se mantuvieron con fotoperiodo de 24 horas luz y con sistema de circulación de agua abierto.

Desde los estanques cónicos, comenzó el seguimiento del desarrollo embrionario bajo microscopio, las larvas fueron sembradas en estanques larvales de 5001 de color negro. Paralelamente se mantuvo un sistema de cultivo de microalgas, a una concentración de 40.000 células $/ \mathrm{ml}$, de especies como Nannochloris atomus, Monochrysis sp. ó Pavlova lutheri e Isochrysis sp., además de un cultivo de rotíferos a una densidad de $2 / \mathrm{ml}$, usado como alimento hasta los primeros 6 días de vida después de la eclosión. La densidad de de larvas en el cultivo larval fue de 2.000 individuos por estanque. Las condiciones de luz y alimentación fueron constantes en este periodo, en cambio la temperatura varió según el protocolo de cultivo del criadero.

Al final del sexto día se evaluaron las condiciones de las larvas, contando las supervivientes de todos los estanques y observando algunas de ellas bajo una lupa, esta observación consistió en la ubicación de la gota oleosa y si la larva se encontraba en forma recta o curva, características fundamentales para la continuidad de la vida larval, según lo observado constantemente en la producción de este cultivo.

Para determinar si existen diferencias significativas en el número promedio de larvas eclosionadas y cosechadas, entre hembras y a tres niveles de temperatura, se realizó un análisis de varianza de dos factores, uno aleatorio (hembras) y el otro fijo (temperatura).

\section{RESULTADOS}

El número de huevos viables para la hembra número uno fue de 180.000 y para la hembra dos de 240.000 (Tabla I). En el desarrollo de los huevos posterior a la fecundación, se observaron huevos con desarrollo irregular y regular (Fig.1). El desarrollo normal (Fig. 2) comienza con la expulsión del primer cuerpo polar, seguido de la segmentación o primera división celular (Fig. 2B). Una segunda división produce como resultado cuatro células o blastómeros (Fig. 2C) que van reduciendo su tamaño progresivamente a medida que siguen las divisiones hasta alcanzar el estado de mórula (Fig. 2D), el cual aumenta el volumen dentro del huevo, generando el blastodisco (Fig. 2E).

La dinámica de divisiones mitóticas de las células del blastodisco aumentó el tamaño de éste, desplazándose como un manto sobre el vitelo, proceso conocido como epibolía (Fig. 2F). Seguido a esto se produce la diferencia- 
Tabla I. Número de huevos de Psetta máxima y temperatura en estanques control y experimentales.

\begin{tabular}{lcccc}
\hline \multirow{2}{*}{ Estanque } & \multicolumn{2}{c}{ Hembra 1 } & \multicolumn{2}{c}{ Hembra 2 } \\
\cline { 2 - 5 } & Temperatura & n de huevos & Temperatura & n de huevos \\
\hline $\mathbf{1}$ (Control 1) & 15,5 & 30.000 & 15,5 & 40.000 \\
$\mathbf{2}$ (Control 2) & 15,5 & 30.000 & 15,5 & 40.000 \\
$\mathbf{3}$ (Experimental) & 12,5 & 30.000 & 12,5 & 40.000 \\
$\mathbf{4}$ (Experimental) & 12,5 & 30.000 & 12,5 & 40.000 \\
$\mathbf{5}$ (Experimental) & 18,5 & 30.000 & 18,5 & 40.000 \\
$\mathbf{6}$ (Experimental) & 18,5 & 30.000 & 18,5 & 40.000 \\
\hline
\end{tabular}

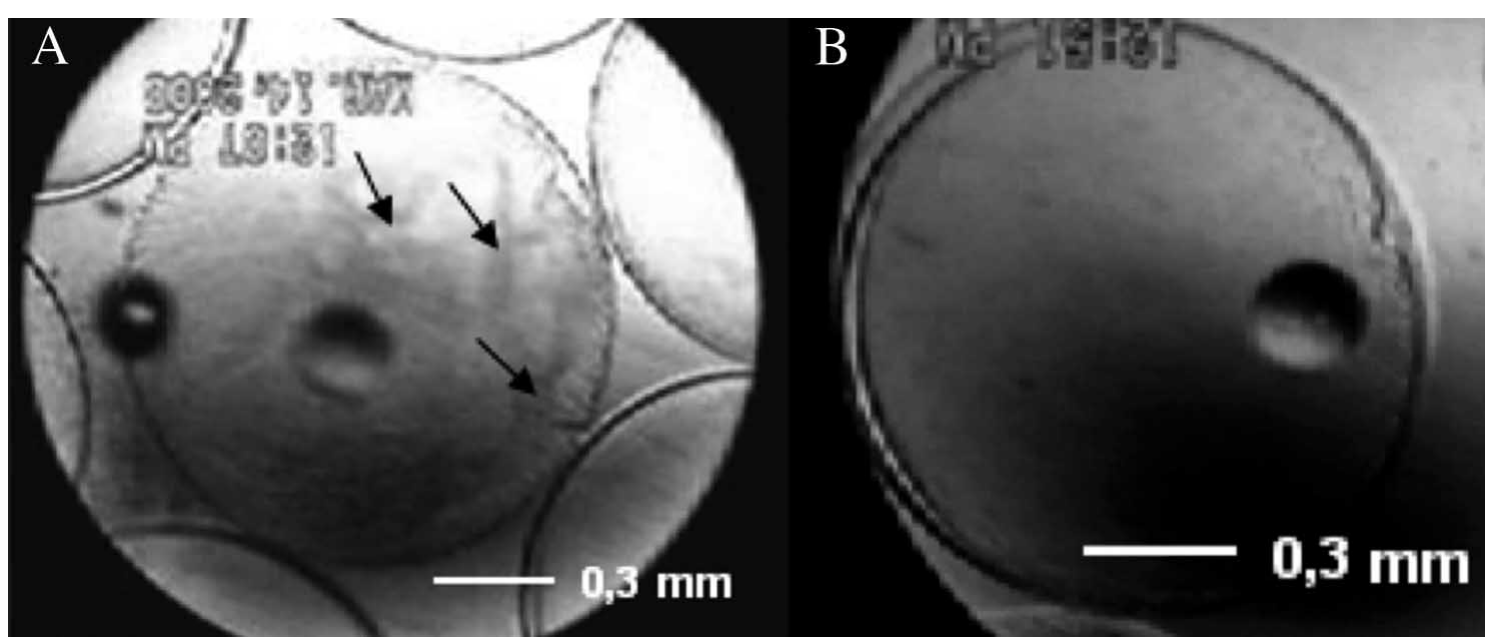

Fig. 1. A. Huevo de Psetta maxima con su blastodisco de desarrollo irregular, se observan abultamientos celulares $(\rightarrow)$ B. Huevo de Psetta maxima con desarrollo normal.

ción de la placa embrionaria o néurula (Fig. $2 \mathrm{G}$ y $2 \mathrm{H}$ ), que es el primer esbozo de un embrión. Transcurridas 42 horas de la fecundación, el embrión ocupa la semicircunferencia del huevo distinguiéndose una parte anterior con las vesículas ópticas y una parte posterior (Fig. 2I). A las 90 horas, el embrión presenta una leve pigmentación, las vesículas ópticas son cada vez más claras y la musculatura presenta metamerización (Fig. 2J, K y L). A las 102 horas el embrión está prácticamente formado, presenta movimientos esporádicos y se puede observar los latidos cardiacos (Fig. 2M). Finalmente, en aproximadamente 115 horas, se rompe el corion, liberando una larva de 2,7 a 3,1 mm de longitud, la cual inicialmente es de carácter planctónico (Fig. 2N).

La mortalidad de los huevos en los tres primeros días de desarrollo fue elevada, $60 \%$ como promedio. Al término del periodo de incubación, los porcentajes de mortalidad para los estanques cónicos con las temperaturas extremas superaron casi el 90\%, manteniendo el $80 \%$ para los estanques controles de $15,5^{\circ} \mathrm{C}$, lo cual se considera normal para este criadero.
El tiempo de eclosión de los huevos de turbot en las diferentes temperaturas reveló que el tiempo de desarrollo en los estanques con temperaturas más altas es menor (99 y 97 horas), contrariamente a los estanques que mantienen una temperatura más baja en los cuales el tiempo de eclosión fue mayor (118 y 116 horas).

Las larvas irregulares se presentaron curvadas y con baja pigmentación, con gota oleosa irregular y/o de posición errónea (Fig. 3). Los huevos recién eclosionados en los estanques control presentaron un $90 \%$ de larvas en buen estado de desarrollo, en cambio, en los estanques experimentales, el porcentaje de larvas bien desarrolladas fue entre 38 y $50 \%$.

La tasa de eclosión mostró porcentajes más altos en los estanques controles 1 y 2, estos son de 16,13\% y $15,64 \%$ para la hembra 1 y $14,01 \%$ y $13,95 \%$ para la hembra 2 . Contrariamente para los estanques 3, 4, 5 y 6 de ambas hembras la tasa de eclosión fluctúa entre $6,77 \%$ a $9,15 \%$, lo que se considera no óptimo para la producción de este criadero. 
El porcentaje de larvas cosechadas a los seis días tras la eclosión del huevo, fluctuó entre un 32 y $35 \%$ para los estanques control, los cuales coinciden con los obtenidos en los cultivos normales para la producción de este criadero. En cambio, para los cultivos experimentales se obtuvieron porcentajes entre 8 y 10 , lo cual está muy por debajo de lo normal.

Los resultados obtenidos con las larvas post-eclosión (Tabla II) muestran que no existe interacción entre las hembras y la temperatura $(\mathrm{p}=0,5203)$. Además, entre las hembras no existen diferencias significativas, puesto que el número de huevos eclosionadas es el mismo. Las diferencias estarían en los niveles de temperatura, con valores significativos ( $\mathrm{p}<0,01)$, alcanzando un mayor número de huevos eclosionados a la temperatura de 15,5 ${ }^{\circ} \mathrm{C}$.

En el número de larvas cosechadas (Tabla III) se obtienen los mismos resultados, es decir, no se encuentran diferencias significativas entre las hembras pero si en los distintos niveles de temperatura $(\mathrm{P}=0,004)$ y la temperatura óptima para ambos experimentos corresponde a $\operatorname{los} 15,5^{\circ} \mathrm{C}$.
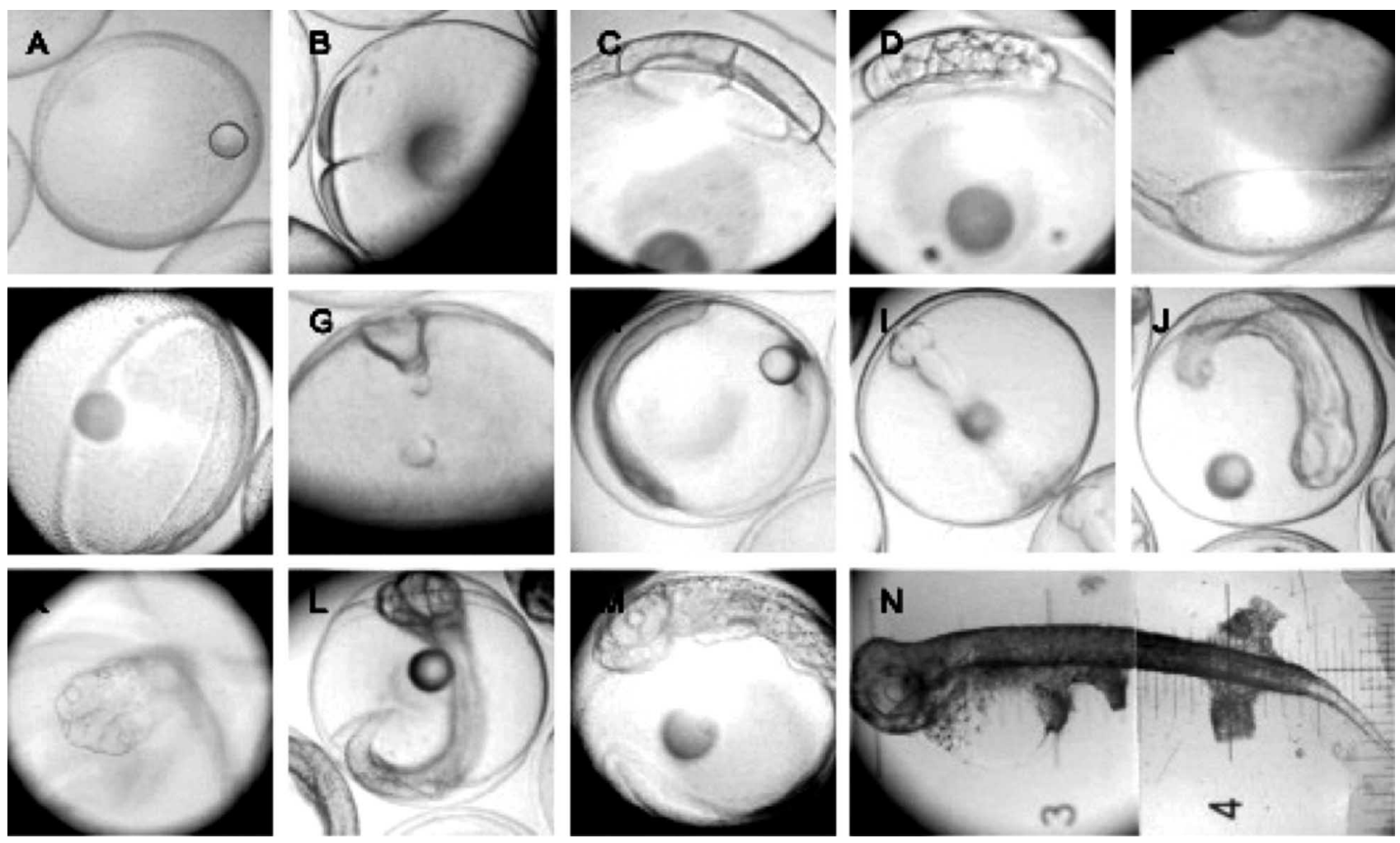

Fig. 2. Desarrollo de los huevos de Turbot. A: huevo. B: primera división celular. C: cuatro células ó blastómeros. D: mórula. E: blastodisco. F: epibolía. G-H: nérula. I: vesículas ópticas. J-K-L: metamerización. M: larva con latidos cardiacos. N: larva de Psetta maxima
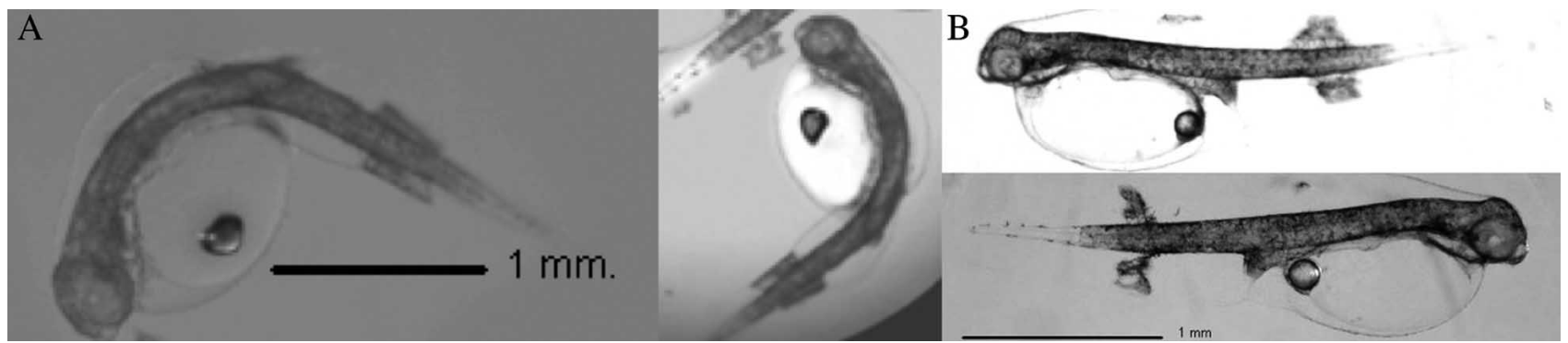

Fig. 3. A: larvas curvadas separadas para su siembra. B: larvas con desarrollo normal, rectas, con gota oleosa ubicada en la parte posterior del saco vitelino, con pigmentación diferenciada. 
Tabla II. Análisis de varianza para la variable larvas post eclosión considerando las hembras $(\mathrm{H})$ como efecto aleatorio y la temperatura $(\mathrm{T})$ como efecto fijo. g.l.= grados de libertad; $\mathrm{SC}=$ suma de cuadrados; $\mathrm{CM}=$ cuadrados medios.

\begin{tabular}{lccccc}
\hline Fuente & g.l. & SC & CM & Valor-F & Valor p \\
\hline $\mathbf{H}$ & 1 & 219308 & 219308 & 4,9 & 0,1572 \\
$\mathbf{T}$ & 2 & 14129904 & 7064952 & 158 & 0,0063 \\
Error: $\mathbf{M S}\left(\mathbf{H}^{*} \mathbf{T}\right)$ & 2 & 89431 & 44716 & & \\
$\mathbf{H} * \mathbf{T}$ & 2 & 89431 & 44716 & 0,73 & 0,5203 \\
Error: $\mathbf{M S}$ (Error) & 6 & 367562 & 61260 & & \\
\hline
\end{tabular}

Tabla III. Análisis de varianza para la variable larvas cosechadas considerando las hembras $(\mathrm{H})$ como efectos aleatorios y la temperatura $(\mathrm{T})$ como efecto fijo. g.l.= grados de libertad; $\mathrm{SC}=$ suma de cuadrados; $\mathrm{CM}=$ cuadrados medios.

\begin{tabular}{lccccc}
\hline Fuente & g.l. & SC & CM & Valor-F & Valor p \\
\hline $\mathbf{H}$ & 1 & 408,333 & 408,333 & 2,59 & 0,2487 \\
$\mathbf{T}$ & 2 & 745807 & 372903 & 2366,39 & 0,0004 \\
Error: $\mathbf{M S}(\mathbf{H} * \mathbf{T})$ & 2 & 315,167 & 157,583 & & \\
$\mathbf{H} * \mathbf{T}$ & 2 & 315,167 & 157,583 & 0,44 & 0,6649 \\
Error: MS (Error) & 6 & 2163 & 360,5 & & \\
\hline
\end{tabular}

\section{DISCUSIÓN}

La importancia de no exceder una densidad de 500 huevos por litro, para obtener un desarrollo óptimo de estos, no concuerda con la densidad usada en esta experiencia, que alcanzó a seis veces más de lo comentado por Blaxter (1981).

En cuanto a las etapas embrionarias, el desarrollo de estas es similar a lo que ocurre en otras especies (Shields et al., 1997; Caballero \& Pinto, 2000), sosteniendo la relación de viabilidad versus desarrollo embrionario, por lo que el desarrollo embrionario permite detectar la condición futura de los huevos que se están incubando (Shields et al.), determinando valores porcentuales de huevos mal formados, siendo este un parámetro importante en el ámbito productivo para la proyección de futuras siembras de larvas al momento de su eclosión (Bobe \& Labbé, 2010).

Predecir la condición futura de los huevos que se están incubando es posible, en estados previos a mórula (4 horas posterior a la fecundación), lo que permitirá determinar algún valor porcentual de huevos viables en etapas más avanzadas, siendo este otro parámetro importante para las proyecciones de futuras siembras de larvas al momento de la eclosión del huevo en criaderos comerciales.
En la secuencia de desarrollo temporal-cualitativo en embriones de turbot, es posible establecer unos parámetros y crear una curva estándar de estos parámetros en función del tiempo. De esta manera se puede comparar un grupo de huevos con dicha curva y así determinar objetivamente en que condición se encuentran (Giménez et al., 2006). En la primera etapa, al inicio de la embriogénesis se puede registrar el número de células como parámetro en la segmentación temprana en relación con un tiempo dado. Para la segunda etapa o etapas más avanzadas será necesario establecer los parámetros a tener en cuenta en las diferentes etapas del desarrollo, ponderándolos en alguna escala y a su vez ser contrastados con una escala de tiempo. De este modo se relaciona dicho patrón, con las características citogenéticas de los embriones en progresión (Kjorsvik et al., 2003).

Un estudio más acabado de este aspecto serviría como una herramienta útil para el diagnóstico temprano del resultado de la manipulación artificial de la reproducción, como son los shocks térmicos en la inducción de la triploidía. Así también, podría observarse si existen diferencias en la tasa de desarrollo o en la calidad de la embriogénesis entre individuos diploides y triploides. 
En la embriogénesis de los huevos de turbot, se demuestra que el tiempo de incubación varía según la etapa de desarrollo y la temperatura de cultivo, siendo las fases iniciales y finales de este proceso el más rápido que en las fases intermedias. Estas observaciones coinciden también para la anchoa y la sardina, donde el tiempo de la incubación disminuyó con el aumento de temperatura (Bernal et al., 2001). Por otra parte, el retraso en el desarrollo en las etapas intermedias (Le Clus \& Malan), es coincidente con el cierre del blastoporo, lo cual conlleva a un aumento en el tiempo de incubación. Jobling (1994) divulgó que la tolerancia termal de los huevos es dependiente de la historia termal anterior y que los cambios compensatorios en el desarrollo fisiológico pueden ocurrir más rápidamente con el aumento de temperatura que con la disminución, tal como se presentan los resultados de esta experiencia.

Respecto a la mortalidad de los huevos en las etapas de desarrollo, Kjorsvik et al. (1984) indicaron que en las últimas etapas embrionarias, una disminución en el crecimiento del huevo puede causar infección bacteriana. Bunn et al. (2000), sugieren que el cambio de la temperatura absoluta que la mayoría de los huevos pueden tolerar, es cercano a los $6^{\circ} \mathrm{C}$ y es dependiente de la presión mecánica de la etapa del desarrollo. Para nuestra experiencia, la tolerancia en temperatura no supera $\operatorname{los} 2^{\circ} \mathrm{C}$, ya que temperaturas superiores e inferiores causan una alta mortalidad de huevos y un deficiente desarrollo larval en sus primeros días. El factor endógeno de la calidad de ovas y espermas y la fertilización artificial, también se sugieren como causas posibles de la mortalidad temprana (Bromage; Brooks et al.).

Al comparar las larvas eclosionadas para las tres temperaturas, se observa que todas mantienen una buena apariencia externa, lo cual nos indica a priori, que no han sido afectadas por la temperatura en el desarrollo embriológico. Sin embargo, el número de larvas sobrevivientes en los diferentes estanques cónicos ratifica una diferencia significativa entre las distintas temperaturas en que se incubaron los huevos.

Los resultados obtenidos a diferentes temperatura como porcentaje de desarrollo normal de huevos recién eclosionadas, tasa de eclosión y porcentaje de larvas cosechadas, en los estanques cónicos que se mantuvieron a temperaturas normales de incubación $\left(15,5^{\circ} \mathrm{C}\right)$, frente a los obtenidos en los demás estanques, muestran una clara evidencia de que las temperaturas experimentales menores y mayores a la del protocolo de cultivo, afectan significativamente la morfología, comportamiento y supervivencia final de las larvas en estudio, tendencia que se repite en la investigación de Radonic et al. (2005)

PEPE-VICTORIANO, R.; ARAYA, M. \& FAÚNDEZ, V. Temperature effect on embryonic survival and early larval stages of Psetta maxima.Int. J. Morphol., 30(4):1551-1557, 2012.

SUMMARY: The mortality rate in embryonic and larval stages of marine fish is associated with the success of a culture, being necessary to optimize the procedures from this to the level of embryonic development and early larval stages for an optimal larval survival and better juvenile production. In order to evaluate temperature effect on embryonic and larval survival of Turbot, fertilized eggs of two reproductives were transferred to the conical incubation tanks at three different temperatures $\left(12.5 ; 15.5\right.$ and $\left.18.5^{\circ} \mathrm{C}\right)$. The eggs that were at extreme temperatures $\left(12.5 \mathrm{y} 18.5^{\circ} \mathrm{C}\right)$ had a minor embryonic development, with a daily mortality rate significantly higher in the first three days and at the end of incubation, especially during the egg eclosion (10\% survival), and without variations at the end of the experiment, when larvae had six days of life. The duration of embryonic development up to the egg eclosion was also determined by incubation temperature, with a higher number of hatched eggs and harvested at the temperature of $15.5^{\circ} \mathrm{C}(20 \%$ survival). Significant differences in the embryonic development of Turbot at three different incubation temperatures indicate the importance of this parameter on the viability of embryonic development and early larval stages of $P$. maxima.

KEY WORDS: Fish's Egg; Turbot; Fish larvae.

\section{REFERENCIAS BIBLIOGRÁFICAS}

Barton, A. L. Egg quality of turbot (Psetta maxima L.) kept in captive conditions. $\mathrm{Ph}$ D. Thesis, University of Liverpool, Liverpool, Great Britain, 1981. p.129.

Bernal, M.; Borchers, D. L.; Valdes, L.; de Lanzos, A. \& Buckland, S. T. A new ageing method for eggs of fish species with daily spawning synchronicity. Can. J. Fish Aquat. Sci., 58(12):233040, 2001.
Blaxter, J. H. S. The rearing of larval fish. In: Hawkins, A. (Ed.). Aquarium Systems. New York, Academic Press, 1981. pp.30323.

Bobe, J. \& Labbé, C. Egg and sperm quality in fish. Gen. Comp. Endocrinol., 165(3):535-48, 2010.

Bromage, N. Broodstock management and seed quality: general 
considerations. In: Bromage, N. R. \& Roberts, R. J. (Eds.). Broodstock management and egg and larvae quality. London, Blackwell Science, 1995. pp.1-23.

Brooks, S.; Tyler, C. R. \& Sumpter, J. P. Egg quality in fish: what makes a good egg? 7(4):387-416, 1997.

Bunn, N. A.; Fox, C. J. \& Webb, T. A literature review of studies on fish egg mortality: Implications for the estimation of spawning stock biomass by the annual egg production method. Funded under MAFF project code MF0426: Fish egg develpoment and mortality studies in the Irish Sea. Science Series Technical Report, 111:1-37, 2000.

Caballero, F. \& Pinto, A. Aproximación experimental al manejo reproductivo del lenguado chileno Paralichthys adspersus (Steindachner, 1867) bajo condiciones de inducción hormonal. Tesis Ingeniería en Acuicultura, Universidad Andrés Bello, Santiago, 2000. p.195.

Giménez, G.; Estévez, A.; Lahnsteiner, F.; Zecevic, B.; Bell, J. G.; Henderson, R. J.; Piñera, J. A. \& Sanchez-Prado, J. A. Egg quality criteria in common dentex (Dentex dentex). Aquaculture 260:232-43, 2006.

Houde, E. D. Fish life dynamics and recruitment variability. Am. Fish. Soc. Symp., 2:17-29, 1987.

Jobling, M. Fish Bioenergetics. London, Chapman and Hall, 1994. p.328.

Jones, A. Incubation of turbot eggs Psetta maxima. In: Iglesias, J. Cuadernos da Área de Ciências Marinas. Sada, Edicions do Castro, 1989. pp.29-36.

Kjorsvik, E.; Hoehne-Reitan, K. \& Reitan, K. L. Egg and larval quality criteria as predictive measures for juvenile production in turbot (Scophthalmus maximus L.). Aquaculture, 227(1-4):920, 2003.

Kjorsvik, E.; Stene, A. \& Lonning, S. Morphological, physiological and genetical studies of egg quality in cod (Gadus morhua L.). Flodevigen Rapportser, 1:67-86, 1984.

Le Clus, F. \& Malan, P. E. Models of temperature dependent rate of development of pilchard, Sardinops sagax eggs, to be used in routine procedures for estimating daily egg production. South Afr. J. Mar. Sci., 16:1-8, 1995.

Legget, W. C. \& Deblois, E. Recruitment in marine fishes: is it regulated by starvation and predation in the egg and larval stages. Neth. J. Sea Res., 32(2):119-34, 1994.

Radonic, M.; López, A.; Oka, M. \& Aristizábal, E. Effect of the incubation temperature on the embryonic development and hatching time of eggs of the red Porgy pagrus pagrus (Linne, 1758) (Pisces: Sparidae). Rev. Biol. Mar. Oceanogr., 40(2):919, 2005.
Ryland, J. S. \& Nichols, J. M. Effects of temperature on the efficiency of growth of plaice prolarvae. Nature, 214:529-30, 1967.

Shields, R. J.; Brown, N. P. \& Bromage, N. R. Blastomere morphology as a predictive measure of fish egg viability. Aquaculture, 155(1-4):1-12, 1997.

Van der Land, M. A. Distribution of flatfish eggs in the 1989 egg surveys in the southern North Sea, and mortality of plaice and sole eggs. Neth. J. Sea Res., 27(3/4):277-86, 1991.

Dirección para correspondencia:

Renzo Pepe-Victoriano

Centro de Recursos Naturales y Medio Ambiente (CERENAYMA)

Escuela Universitaria de Ingeniería Industrial e Informática y Sistema (EUIIIS)

Universidad de Tarapacá

Arica

CHILE

Email: rpepe@uta.cl

Recibido : 20-03-2012

Aceptado: 03-07-2012 